\title{
Investigation and Analysis of Urban Spatial Structure around the Train Stations in Kitakyushu by Using Space Syntax and GIS
}

\author{
Jianan Liu, Danhua Wu, Fukahori Hidetosi, Weijun Gao \\ Department of Architecture, The University of Kitakyushu, Kitakyushu, Japan \\ Email: soralja@hotmail.co.jp
}

Received 16 February 2015; accepted 6 March 2015; published 12 March 2015

Copyright (C) 2015 by authors and Scientific Research Publishing Inc.

This work is licensed under the Creative Commons Attribution International License (CC BY). http://creativecommons.org/licenses/by/4.0/

(c) (i) Open Access

\begin{abstract}
Although many methods of spatial analysis have been developed for a better understanding and modelling of urban space analysis, there is still a need for exploration of new analytical techniques for modelling urban spaces. Space Syntax models the spatial configurations of urban spaces by using a connectivity graph representation. Such a configuration of space identifies patterns that can be used to study urban structures and human behaviors. This paper tries to present a new methodology to investigate the urban spatial structure by using Space Syntax with the GIS information including land use, buildings' characteristics and practical evaluations of the potential of the Space Syntax approach with GIS and multivariate analysis technique. Finally we try to offer some recommendations that attempt to improve the identified problems faced in Kitakyushu, Japan.
\end{abstract}

\section{Keywords}

Spatial Structure, Space Syntax, Land Use, GIS

\section{Introduction}

Nowadays, a number of cities have been experiencing serious problems in their city centers mostly from urban sprawl, decline of CBD and population decrease and aging. Kitakyushu is also facing the same problems. Urban structure has been changed because of complex factors which consist of politics, economy, sociality and culture. There is vertical growth caused by higher-rising buildings and horizontal growth caused by outskirts development in a city. In this paper, we reconsider the situation of development around the train station in Kitakyushu. A new approach to analyze the urban space characteristics has been proposed in this paper. This new approach provides useful information about the best routes or streets in the district or city to reach to station from the 
point of view of quality in the accessibility. Our research analyzes station areas in Kitakyushu regarding their capacity to attract inhabitants. This capacity of attraction could be established depending on the design and associated facilities that public spaces provide. The main result of this study emphasizes the role of integration as a key factor in the people's movement around the train station.

The Space Syntax and GIS have been successfully applied to many urban studies, and the axial map is well used to predict human spatial behavior. It is one of the effective methods to analysis the urban space. The success of Space Syntax is well proven in urban planning and is being further in predicted human behaviors. However, researchers in the Space Syntax community claimed, through enormous empirical studies (Hillier et al., 2001) [1], human movement can be predicted by local integration. And Space Syntax is also recognized as the key alternative for urban planning in order to redevelop the decline city. Especially, Space Syntax for Japan's urban planning by using axial map, it is effective method in order to improve the city environment. Rubén TALAV ERA [2] improved pedestrian accessibility to public space through Space Syntax analysis. The author analyze about the location of public space at different scales of the spatial structure of the city of Granada. The results of spatial configuration analysis in Granada show that there are great differences inside the service area of the district parks, providing a new point of view to the space-time measures. These differences make a public space more integrated or visible than others into a quarter, district or city. Bin Jiang [3] proposed methodological and practical evaluations of the potential of the Space Syntax approach within GIS. Hong-Kyu Kim [4] investigated the relationship between urban street configuration and land use density of office buildings in Seoul, Korea. Deniz Erinsel Önder [5] in his study was to implement a methodology to determine the social and physical problems of a historical urban space and subsequently to offer recommendations that attempt to improve the identified problems. Frank van der Hoeven [6] explored the potential use of the Space Syntax methodology for evaluating user way finding, orientation and visibility in urban underground space. Ayman Hassaan Mahmoud [7] investigated the influence of spatial configuration produced by the proposed tree planting design on the visual fields of an urban park using Space Syntax theory.

Although many methods of spatial analysis have been developed for a better understanding and modelling of urban space analysis, there is still a need for exploration of new analytical techniques for modelling urban spaces. Space Syntax models the spatial configurations of urban spaces by using a connectivity graph representation. Such a configuration of space identifies patterns that can be used to study urban structures and human behaviors.

Based on those pervious researches, this paper tries to present a new methodology to investigate the urban spatial structure by using Space Syntax with the GIS information including land use, buildings' characteristics and practical evaluations of the potential of the Space Syntax approach with GIS and multivariate analysis technique. Finally we try to offer some recommendations that attempt to improve the identified problems in Kitakyushu, Japan.

\section{Methodology}

This study explored the combination of Space Syntax theory and GIS database to analysis the spatial characteristics of the center areas of Kitakyushu, Japan. And then we use multivariate analysis technique to find out the elements which affect the space performance. This methodology provides a simple way to have an analysis and evaluation for city planning and redevelopment and the spatial characteristics of city. This paper based on two key ideas: Connectivity and spatial configuration as follows. The connectivity is the simplest metric for assessing ranking of nodes within a connectivity graph. It equals the number of directly linked or neighboring nodes, which is called a local measure. The spatial configuration plays a primitive or principal role for the pedestrian mobility. The spatial configuration affects to pedestrians when they have to take the decision about what route they select for their trips. So the spatial configuration could encourage or discourage the election of a route about which pedestrian can to arrive to the opportunities, even more if the streets have different design properties. This effect of spatial configuration on pedestrian mobility has created a new concept in planning studies, the concept of "the natural movement". This natural movement is based on the distribution of configuration values in the axial map called integration. Under the theory of Space Syntax the proposed integration measures the degree in which a node is integrated or segregated respect of a part of total (local integration) or the whole (global integration). In the Space Syntax community which developed the theory and the practice of this measure, the integration is linked to the concept of accessibility and connectivity in terms of spatial configuration, 
which is called a global measure.

\subsection{Space Syntax}

Space Syntax theory is put forward by professor Bill Hiller (UCL) has been a powerful tool to analyze urban form combining people movement with spatial configuration and makes use of impersonal, and accurate approach to describe the spatial configuration pattern of city and architecture. Space Syntax is a method for describing and analyzing the relationships between spaces of urban areas and buildings.

Now, Space Syntax has been successfully applied to many urban GIS studies, it is both a theory of urban planning and design and a software-based technology. It is an evidence based approach to planning and design, through the structural analysis of an urban environment, we can derive a better understanding of the evolution of urban areas to help with the design of new urban layouts.

There are five elements in Space Syntax analysis:

1) Connectivity

In space system, the higher connectivity value, the better space permeability.

2) Control value

The control degree of the adjacent nodes.

3) Depth

The shortest average in system to a node to all other nodes, the average value is called the nodes deep value.

4) Integration

The space liquidity can be controlled by Int. values. The higher Int. values, the greater centre space effect. From other space is relatively easy to arrive, a more active in all fields of space. If the Int. value is low, it shows that space is relatively quiet.

5) Intelligibility

If connectivity value and Int. value are higher, this understandability of space system is better.

Those five factors in the integration value are the most important indicators.

\subsection{Axial Map}

Axial analysis is one of analysis method of Space Syntax. It is frequently used by the analysis of urban space. The theory of the study is put forward by integrating Space Syntax with the image of city.

The relationship between the apex of axial line and adjacent line shows by the diagram form to numerical analysis superior or inferior on efficiency. Axial maps can be transformed into graphs for purpose of analysis:

- Graph is a figure representing the relationships of permeability between all the convex spaces or axial spaces of a layout. The spaces are represented by nodes and the links with lines. It is possible to use links in order to represent relationships of visibility between spaces.

- Depth between two spaces is defined as the least number of syntactic steps in a graph that are needed to reach one from the other.

Figure 1 shows a simple version of an axial map and the associated graph. With the figure, it is relatively easy to understand the morphological measures introduced above. First of all, connectivity is the number of nodes directly linked to each individual node. For instance, line 1 (or node 1 in the associated graph) in Figure 1 has connectivity of 3 , and line 2 has connectivity of 1 . The relationship between the apex of axial line and adjacent line shows by the diagram form to numerical analysis superior or inferior on efficiency.

What keeps Space Syntax model for spatial cognition is that it is a computational model. In other words, with the computational model by analyzing morphological structure human spatial behavior is predictable. For instance, extensive empirical studies over the past decade have demonstrated that pedestrian rates strongly correlate to local integration value (Hillier et al., 1993). In many cities, spatial analysis is widely used.

The control value for a line is determined according to the following calculation, where $n$ is the number of immediate neighbors of a space and $C_{j}$ is the connectivity of the $j$ immediate neighbor of the space.

$$
\operatorname{ctrl}_{i}=\sum_{j-1}^{n} \frac{1}{C_{j}}
$$

According to the definition of depth, for each axial line, all other lines should be traversed in order to retain the so called mean depth (MD), 

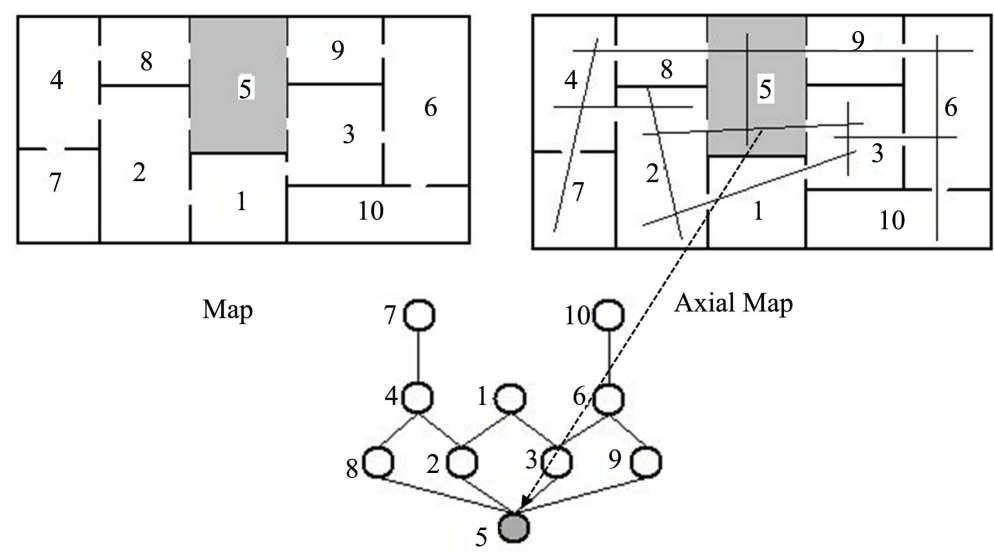

Figure 1. Axial map process and the associated graph.

$$
\begin{gathered}
\mathrm{MD}_{i}=\frac{\sum_{j-1}^{n} d_{i j}}{n-1} \\
\mathrm{RA}_{i}=\frac{2\left(\mathrm{MD}_{i}-1\right)}{n-2}
\end{gathered}
$$

where $n$ is the number of spaces and $\sum_{j-1}^{n} d_{i j}$ is the total depth of the $i$ axial line. For measuring integration and segregation property, MD is sufficient. Relative Asymmetry (RA) is employed to standardize MD between 0 and 1 .

MD: The average depth of all axial line;

$k$ : Axial line the total number of

$$
\begin{gathered}
\mathrm{RA}=2 \frac{(\mathrm{MD}-1)}{(k-2)} \\
\mathrm{RRA}=\frac{\mathrm{RA}}{D x} \\
D x=\frac{2\left(k\left(\log 2\left(\frac{k+2}{3}\right)-1\right)+1\right)}{(k-1)(k-2)}
\end{gathered}
$$

RA depend on $k$ values, after the use of relative of RA, the Real Relative Asymmetry (RRA) calculate the relative depth.

In order to more easily understand the RRA, taking its reciprocal, called integration value. After the geometric index of the value, if integration is higher and the distance is short, the efficiency of moving is higher. The pedestrian are more, too. In the other side of the case, if integration is lower, that the efficiency of moving is lower, it is a relatively quiet space.

$$
\text { Integration value }=\frac{1}{\text { RAA }}
$$

\section{Case of Study}

In Japan, most of city has been developed along the railway. Kitakyushu City is the same, too. Kitakyushu as an industrial advanced area has became the multi nodal city and provided enormous support for the modernization, after the Meiji period. Kitakyushu City was created by the amalgamation of the five cities in 1963 and since then with the change of economic and the development of society, the urban structure in this city has changed enormously. There were more than one million people in 1980 at the populous period. But since then there has been 
a steady decrease in population in this city. Today there is nine hundred ninety-nine thousand seventy-one population. Because of population decrease and adjustment of the industrial structure, the urban center is developing slowly. The motorization and suburbs expansion of the city site accelerate aging of urban population and the building deterioration significantly. Daily population flow change is very intense because urban area of the city is concentrated in the commercial and industrial sectors. Due to the transformation of the industrial structure and declining industry, there are many problems in the city structure.

After the plan of renaissance in 1989, Kokura had become the center of Kitakyushu and Kurosaki had become a sub-center of Kitakyushu. This paper uses Space Syntax theory and GIS to analysis the present situations of urban spatial structure and the effective measures of downtown revitalization. The study areas in this paper are defined as the space with $2 \mathrm{~km}$ radius in front of station. It is a typical linear city and $2 \mathrm{~km}$ radius of station centers as shown in Figure 2.

\section{Spatial Configuration}

Kitakyushu as an industrial advanced area since Meiji period provided enormous support for the modernization. The urban core of metropolitan area of Kitakyushu was created by in 1963 by the amalgamation of the five cities of this area and since then with the change of economic and the development of society, the urban structure in this city had changed enormously. This study set the radius of $2 \mathrm{~km}$ area from station which pedestrians can walk within 30 minutes as study area. The results of integration from the Figure 3 and Figure 4 showed global integration of the road in Kokura and Kurosaki, respectively. The red line represented the maximum connectivity, and the blue line represented for the minimum connectivity.

The basic spatial morphological structure is readable, for instance where the integrated areas are and where the segregated areas are. The red scale of lines represent for maximum integration around 1.49 to 1.87 . The blue scale of lines represent for minimum integration around 0.62 to 0.77 . From the Table 1 , we can clearly see that the average integration in Kokura is higher than in Kurosaki. When integration is higher, it means that place provide a large number of possible decisions about selection of routes in the pedestrian movement. And that place is really activity. From the Table 1, the average integration value of Kokura area is 1.101 and Kurosaki area is 1.082, it mean the Kokura area have much more accessibility than Kurosaki area.

\subsection{Connectivity}

Connectivity is the simplest metric for assessing ranking of nodes within a connectivity graph. It equals the

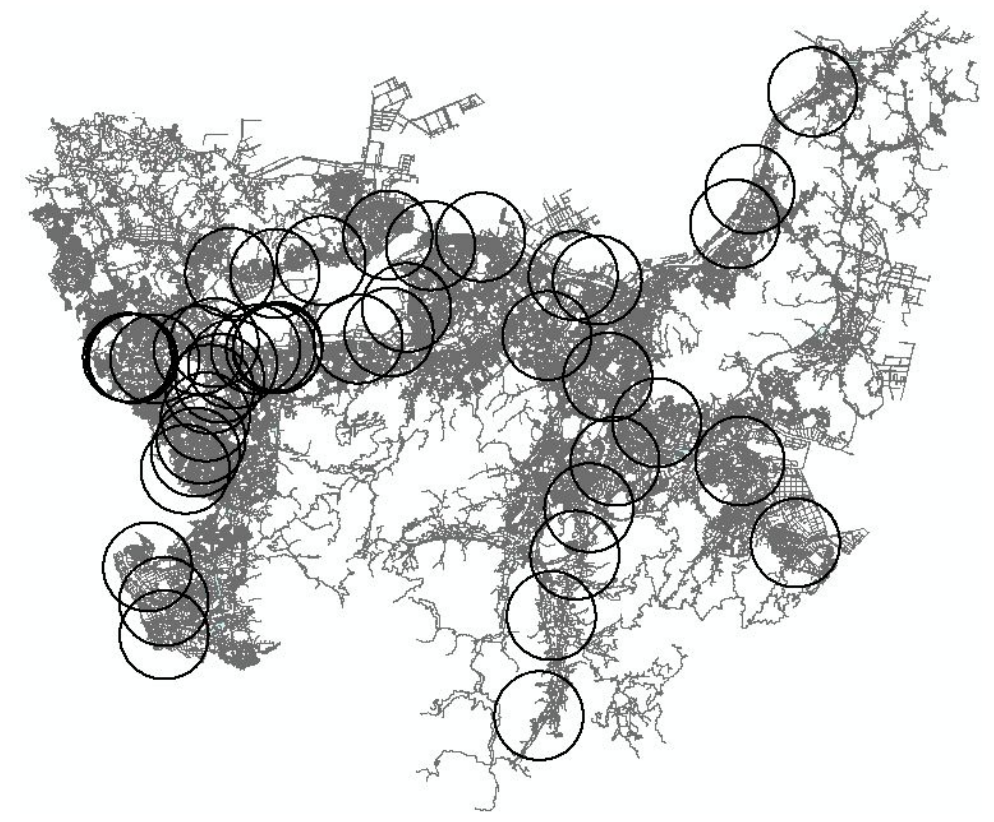

Figure 2. A linear town in $2 \mathrm{~km}$ radius of stations. 


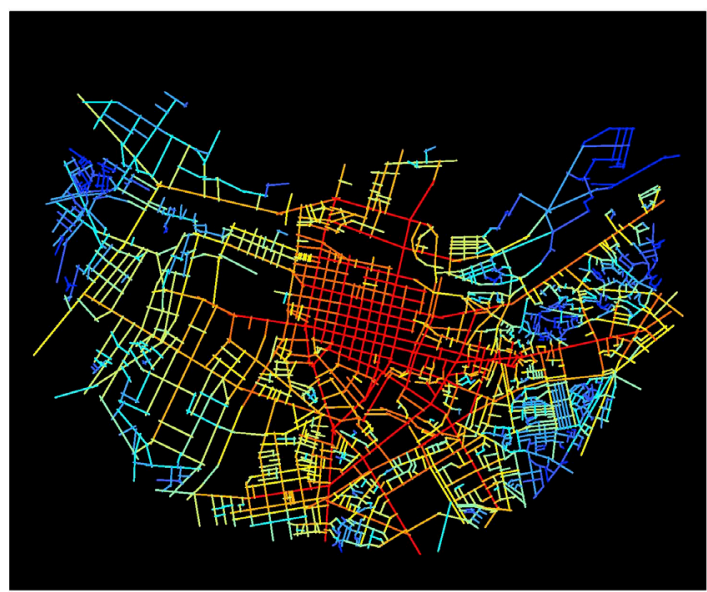

KOKURA Integration

- $0.62205-0.77351$

$-0.77352-0.87155$

$0.87156-0.95876$

$0.95877-1.02901$

$-1.02902-1.10175$

$1.10176-1.18164$

$1.18165-1.26659$

-1.26660 - 1.37084

-1.37085 - 1.49487

- 1.49488 - 1.87118

Figure 3. Kokura axial map colored with global integration.

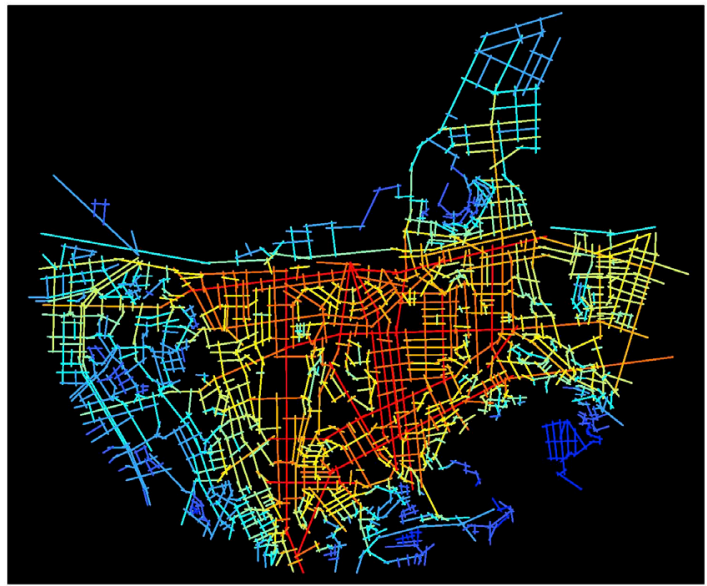

KUROSAKI Integration INTEGRATIO $0.30876-0.55840$

- $0.55841-0.77701$

$0.77702-0.90889$

$0.90890-1.01255$

- $1.01256-1.10540$

1.10541 - 1.19865

$1.19866-1.29228$

-1.29229 - 1.39697

$-1.39698-1.53780$

$-1.53781-1.78587$

Figure 4. Kurosaki axial map colored with global integration.

Table 1. The global integration of Kokura and Kurosaki.

\begin{tabular}{cccccc}
\hline Area & Maximum & Minimum & total & Average & Standard \\
\hline Kokura & 1.8712 & 0.6221 & 1925.41 & 1.11 & 0.22 \\
Kurosaki & 1.7859 & 0.3088 & 1416.16 & 1.08 & 0.25 \\
\hline
\end{tabular}

number of directly linked or neighboring nodes. The connectivity analysis of the city of Kitakyushu shows in the Figure 3 and Figure 4. It could be observed how Kokura area has axes with high connectivity values. But Kurosaki is surrounded by low connectivity axes than Kokura. According to the results, Kokura area has a better connectivity than Kurosaki area and therefore it can offer more opportunities for decision from these axes with high connectivity. The highest values of connectivity provide a large number of possible decisions about selection of routes in the pedestrian movement.

\subsection{Integration}

One of the important measures related to connectivity and accessibility in Space Syntax is the measures of integration. The axes with the highest integration values will be most accessible and connectable. According to the global integration values of Kokura and Kurosaki in Figure 3 and Figure 4, we can observe that the highest global integration values happened in front of the Kokura station. In other words, Kokura station has the highest integration. And the streets intersect with high values of global integration. However, compared with Kokura, 
less integration axes are located in Kurosaki. Kurosaki has less connectivity and accessibility than Kokura. The average values shown in Table 1 . These values means that pedestrian movement move along these streets, the highest value represent for the pedestrian activities is highest.

Regarding global integration analysis, Kokura is surrounding by lines with high value of global integration, and high streets which in front of Kokura station are less integration in the whole area of Kokura. So the area in front of Kokura station has constant use by people and this is a bustling area. Kokura is located in a better site, Kokura castle, Matsumoto Memorial Museum and the city's central train Kokura station are all located in that area.

Although Kurosaki is located with low integration than Kokura, the global value is still very high. Concerning local integration, the existing differences caused the global value differences.

\subsection{Multivariate Analysis}

The Integration value represents the best connectivity between spatial extent and high degree of mobility. Observed variables influence by other variables, so the factor analysis in addition to observed variables, but also assumes there are some latent variables assumed. Between the observed variables are linked to the premise, to identify influential factors, use the results of the strength of the relationship of factors to explain. Ranks among the variables, the election regulations, the potential factors related functions of the statistical methods.

Make use of the formula:

Measured value of project $=$ Common characteristic values + the independence of the project.

Analysis formula:

Basis type of analytic model:

$$
Z_{i j}=\sum_{i=1}^{m} a_{j p} f_{i p}+d_{j}^{2} u_{i j}
$$

$Z_{i j}$ : the scores after assessed the value of benchmarking;

$a_{j p}$ : factor loading;

$f_{i p}:$ factor scores;

$d_{j}^{2}$ : the independence;

$u_{i j}$ : the independence of factors.

Each of ten spaces were elected within the maximum Int. value from Kokura Figure 5 and Kurosaki Figure 6 and use the main facilities of GIS spatial datasets, Table 2, Table 3, this paper analysis the potential elements of the impression spaces. Firstly, this study according to the datasets of ten spaces A to G in Kokura by a more details investigation.

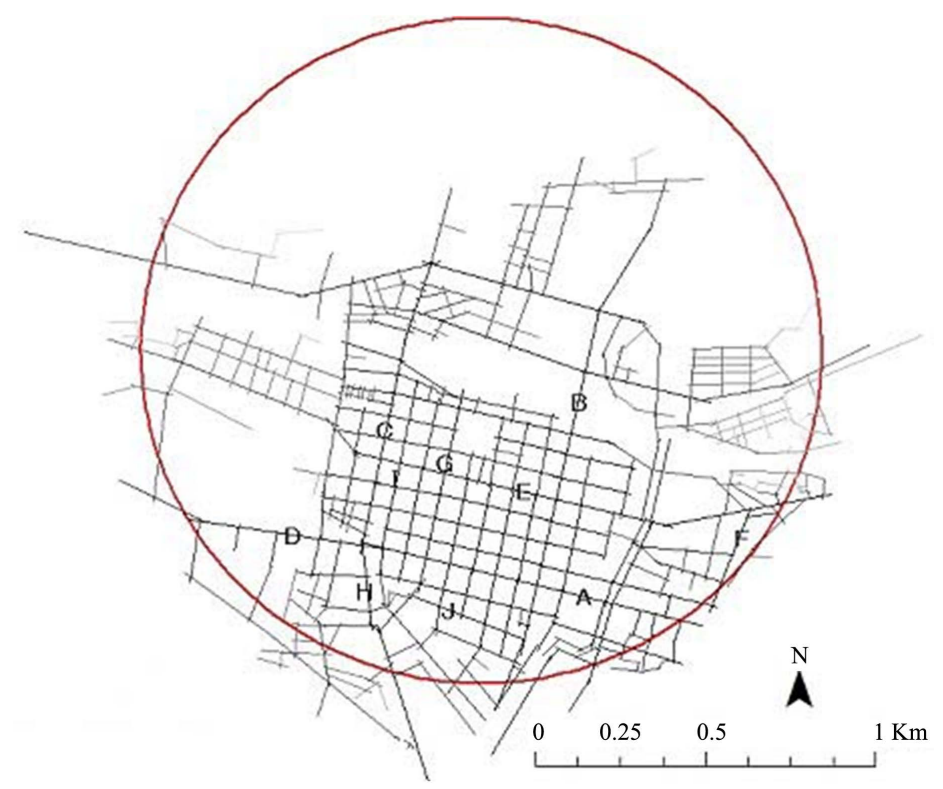

Figure 5. Ten streets were selected in Kokura. 


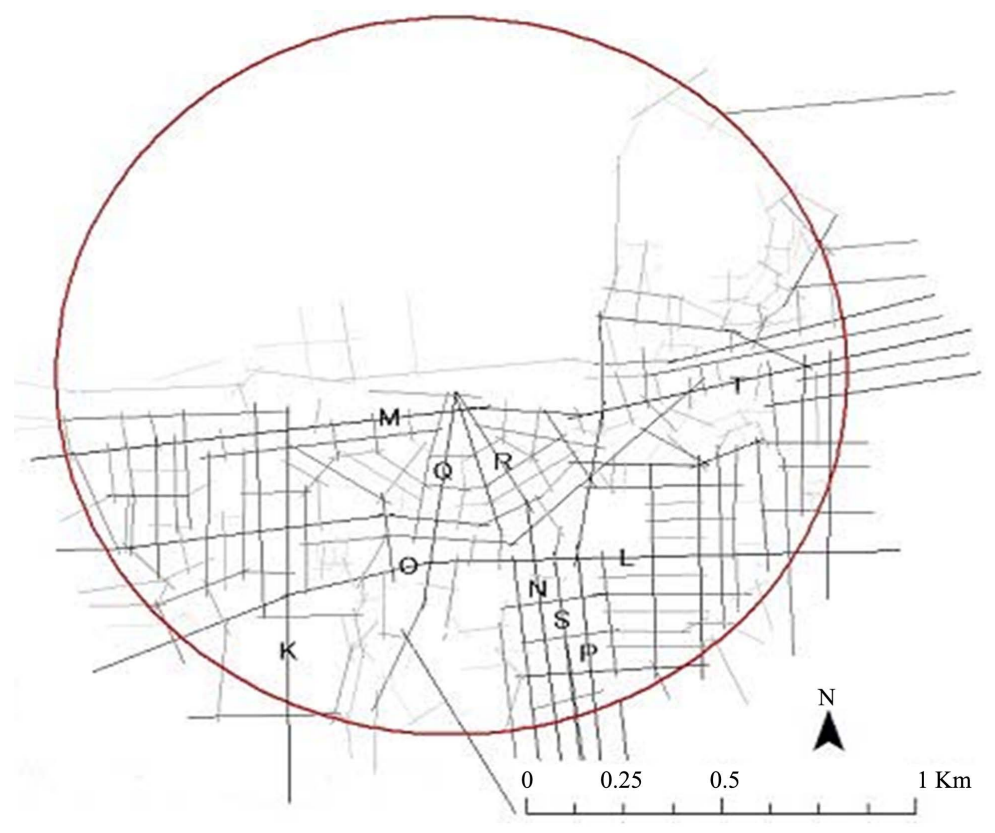

Figure 6. Ten streets were selected in Kurosaki.

Table 2. The integration of each ten streets with existing land use in Kokura.

\begin{tabular}{|c|c|c|c|c|c|c|c|c|c|c|}
\hline Sign & Int. & $\begin{array}{l}\text { Width } \\
\text { (m) }\end{array}$ & $\begin{array}{l}\text { Length } \\
\text { (m) }\end{array}$ & $\begin{array}{l}\text { Municipal } \\
\text { offices }\end{array}$ & Education & Commerce & Amusement & Business & Financing & Service \\
\hline A & 1.86363 & 30 & 1042 & 7 & 5 & 45 & 0 & 20 & 8 & 23 \\
\hline $\mathrm{B}$ & 1.85494 & 25 & 1025 & 0 & 9 & 31 & 0 & 17 & 4 & 13 \\
\hline C & 1.70848 & 15 & 663 & 0 & 10 & 56 & 10 & 9 & 2 & 13 \\
\hline $\mathrm{D}$ & 1.68219 & 30 & 535 & 2 & 2 & 6 & 0 & 2 & 0 & 8 \\
\hline E & 1.67492 & 19 & 970 & 0 & 14 & 41 & 2 & 24 & 10 & 21 \\
\hline $\mathrm{F}$ & 1.67423 & 25 & 372 & 0 & 0 & 6 & 0 & 5 & 0 & 8 \\
\hline G & 1.66692 & 39 & 560 & 2 & 6 & 30 & 0 & 18 & 10 & 28 \\
\hline $\mathrm{H}$ & 1.66151 & 18 & 236 & 0 & 6 & 17 & 0 & 5 & 0 & 13 \\
\hline I & 1.65231 & 5 & 255 & 0 & 4 & 69 & 8 & 0 & 0 & 36 \\
\hline $\mathrm{J}$ & 1.64642 & 4.5 & 314 & 0 & 4 & 22 & 3 & 6 & 0 & 19 \\
\hline Total & 1708555 & 210.5 & 5972 & 11 & 60 & 323 & 23 & 106 & 34 & 182 \\
\hline Average & 1.70856 & 21.5 & 597.2 & 1.1 & 6 & 32.3 & 2.3 & 10.6 & 3.4 & 18.2 \\
\hline Deviation & 0.081 & 11.031 & 317.614 & 2.234 & 4.082 & 20.753 & 3.713 & 8.409 & 4.326 & 9.028 \\
\hline
\end{tabular}

These streets were classified into different kinds of facilities, according to their characteristics. The classification of street gives us a result a total of 7 types. We can easy to see the status of the street areas. These types are: government and municipal offices, education, commerce, amusement, business, financing and service.

The connectivity analysis of 2 station areas shows a gap in the results. Some of them are concentrated in very high values and the rest of them in very low values of connectivity. The highest values of connectivity were selected, there are: factor 1 , factor 2 and factor 3 . Arranged on the top of the integration value, factor 1 is the highest, followed by factor 2 , and finally is factor 3 . 
Factor analysis results shown in Table 5 . The effect degree of 1 is ordered from 1 to 3 in the descending order of priority. The total of ratio of factor in Kokura is $82.9 \%$, the degree of its shows more than $80 \%$. The total of ratio of factor in Kurosaki is $79.6 \%$ level of close to $80 \%$. The ratio is greater, the association is stronger.

From factor 1, we can see very clearly. The financial services facilities in center of Kokura show the prominent characteristics (Table 4), but it is opposite in Kurosaki, the spatial characteristics in terms of the municipal offices and educational facilities are prominent (Table 5).

Table 3. The integration of each ten streets with existing land use in Kurosaki.

\begin{tabular}{ccccccccccc}
\hline Sign & Int. & Width $(\mathrm{m})$ & $\begin{array}{c}\text { Length } \\
(\mathrm{m})\end{array}$ & Municipal offices & Education & Commerce & Amusement & business & Financing & Service \\
\hline K & 1.78587 & 25 & 1677 & 3 & 11 & 27 & 0 & 17 & 0 & 6 \\
L & 1.78337 & 18 & 1165 & 3 & 20 & 12 & 2 & 12 & 2 & 10 \\
M & 1.76023 & 25 & 1134 & 1 & 8 & 30 & 1 & 19 & 1 & 9 \\
N & 1.73738 & 10 & 1034 & 0 & 8 & 25 & 0 & 6 & 1 & 5 \\
O & 1.72151 & 18 & 373 & 0 & 7 & 5 & 1 & 2 & 0 & 2 \\
P & 1.6731 & 15 & 971 & 0 & 4 & 8 & 0 & 12 & 0 & 4 \\
Q & 1.67282 & 22 & 560 & 0 & 14 & 25 & 4 & 10 & 2 & 6 \\
R & 1.6487 & 10 & 313 & 0 & 4 & 37 & 4 & 2 & 1 & 16 \\
S & 1.63413 & 6 & 693 & 0 & 2 & 10 & 0 & 1 & 1 & 2 \\
T & 1.5992 & 25 & 958 & 1 & 10 & 23 & 2 & 28 & 0 & 10 \\
Total & 17.01631 & 174 & 8878 & 8 & 88 & 202 & 14 & 109 & 8 & 70 \\
Average & 1.701631 & 17.4 & 887.8 & 0.8 & 8.8 & 20.2 & 1.4 & 10.9 & 0.8 & 7 \\
Deviation & 0.065 & 6.995 & 412.894 & 1.229 & 5.329 & 10.696 & 1.578 & 8.685 & 0.789 & 4.320 \\
\hline
\end{tabular}

Table 4. The highest factors of Kokura.

\begin{tabular}{ccccc}
\hline Kokura & Factor 1 & Factor 2 & Factor 3 & Commonness \\
\hline Integration & 0.715 & -0.110 & 0.120 & 0.959 \\
Width (m) & 0.622 & -0.597 & 0.115 & 0.950 \\
Length (m) & 0.914 & 0.074 & -0.192 & 0.964 \\
Municipal offices & 0.611 & -0.231 & 0.665 & 0.902 \\
Education & 0.518 & 0.579 & -0.591 & 0.956 \\
Commerce & 0.182 & 0.924 & 0.256 & 0.985 \\
Amusement & -0.374 & 0.816 & 0.006 & 0.976 \\
Business & 0.934 & 0.125 & -0.213 & 0.994 \\
Financing facilities & 0.889 & 0.176 & -0.002 & 0.978 \\
Service & 0.132 & 0.669 & 0.564 & 9.65 \\
Total number & 4.228 & 2.777 & 1.284 & $13.30 \%$ \\
Contribution rate & $43.80 \%$ & $28.80 \%$ & $12.80 \%$ & \\
Ratio of factor & $42.30 \%$ & $27.80 \%$ & & \\
\hline
\end{tabular}


Table 5. The highest factors of Kurosaki.

\begin{tabular}{ccccc}
\hline Kurosaki & Factor 1 & Factor 2 & Factor 3 & Commonness \\
\hline Integration & 0.615 & -0.278 & 0.526 & 0.958 \\
Width (m) & 0.777 & 0.032 & -0.3346 & -0.054 \\
Length (m) & 0.799 & -0.451 & 0.181 & 0.946 \\
Municipal offices & 0.886 & -0.113 & 0.449 & 0.905 \\
Education & 0.756 & 0.249 & -0.332 & 0.940 \\
Commerce & 0.269 & 0.649 & 0.022 & 0.969 \\
Amusement & -0.023 & 0.946 & -0.573 & 0.941 \\
Business & 0.734 & -0.013 & 0.702 & 0.848 \\
Financing facilities & 0.086 & 0.583 & -0.224 & 0.910 \\
Service & 0.279 & 0.803 & 1.616 & 9.368 \\
Total number & 3.676 & 2.658 & $17.20 \%$ & $16.20 \%$ \\
Contribution rate & $39.20 \%$ & $28.40 \%$ & $26.60 \%$ & \\
Ratio of factor & $36.80 \%$ & &
\end{tabular}

From the part of Kokura area, we can see there are the highest value shown in lengths, business facilities and financial facilities. And also the integration is high, too. It's easy to find this space is very convenient. The impact factor of commercial and entertainment facilities shown in factor 2 are very high and the public official facilities in factor 3 have great impact on pedestrian movement. This space has its own particularity that is business and financial system as the center. We can know the financial and business facilities are configured in the convenience space, in other words, Kokura is a Commercial and financial center.

From the factor 3 of Kurosaki, the executive and educational facilities, health benefits are relatively strong in financing facilities.

Although from the land use data to analyze the highest factor in Kokura and Kurosaki, the gap is not very obvious. But from spatial configuration, it is very clearly to see that integrations are very different.

According to data from Table 4, to better understand, we have produced this data radar chart. Figure 7, Figure 8, there are good mobility features space diagram in those two areas. Because the two areas are to be calculated independently, so the size of the load factor cannot be compared. Only expresses the geographical factors influence the intensity. Although not all of these areas features of spatial data, but still showed the spatial characteristics of the two areas. The financial services facilities in center of Kokura for the prominent characteristics, but the financial impact is weaker in Kurosaki, the executive and cultural and educational facilities in the spatial characteristics are prominent.

\section{Conclusion and Future Research}

In this study, the results of spatial configuration analysis in Kitakyushu show that there are some differences in the center of city and sub-center of city. Both Kokura and Kurosaki have the same extension and provide similar service area. The average integrations of factor are shown in Table 6. Kokura is more connectable and accessible than Kurosaki in terms of spatial configuration. Kokura is surrounded by Kokura castle and museums with better connectivity, streets with a higher level of global and local integration that collects the pedestrian fluxes. The spatial configuration plays an important role in the environment quality of pedestrian accessibility in urban planning.

Factor analysis of multiple variables with Kokura and Kurosaki shows a good flow of the main streets of the spatial characteristics in Figure 7 and Figure 8. To attract customers, or the convenience of the facilities, a choice for high traffic conditions is good in the site orientation. By factor analysis, we know that the financial, 


\section{Kokura}

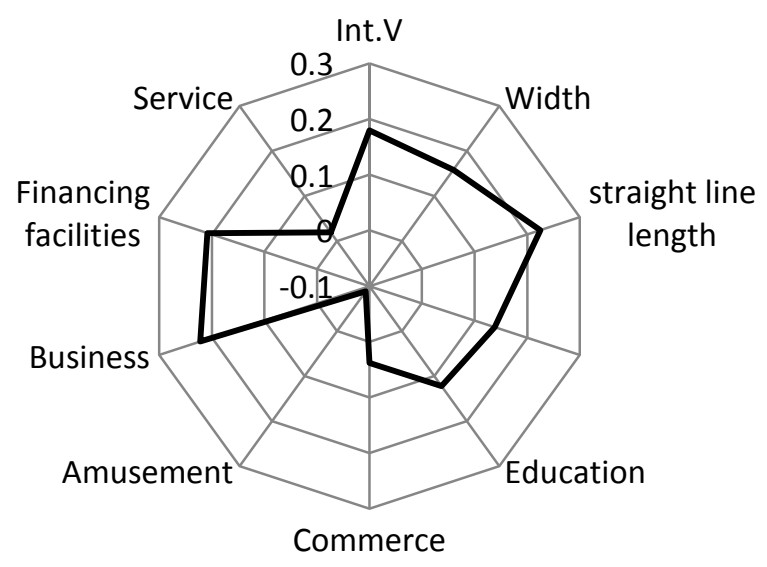

Figure 7. Kokura district space characteristic.

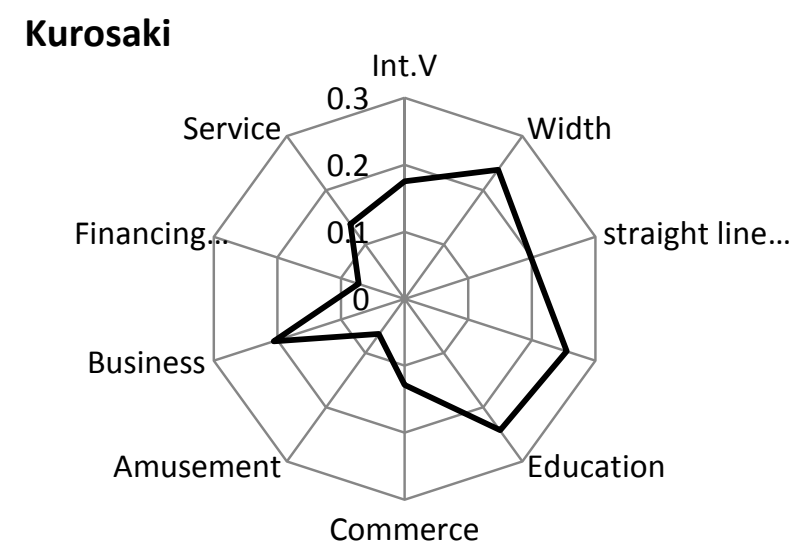

Figure 8. Kurosaki district space characteristic.

Table 6. The average integrations of factor.

\begin{tabular}{ccc}
\hline Factor loadings & Kokura & Kurosaki \\
\hline Integration & 0.179794071 & 0.175363081 \\
Width (m) & 0.158156921 & 0.237740719 \\
Length (m) & 0.224563439 & 0.19853782 \\
Municipal offices & 0.137778616 & 0.254920267 \\
Education & 0.121750191 & 0.242848573 \\
Commerce & 0.037689264 & 0.128801891 \\
Amusement & -0.088674996 & 0.065559166 \\
Business & 0.221791721 & 0.205851304 \\
Financing facilities & 0.208100889 & 0.072502181 \\
\hline
\end{tabular}

commercial, operational, administrative agencies and other facilities are highly accessible spaces. In that case, the integration shows the degree of connectivity and accessibility. Space Syntax can predict the future use of the distribution of business type facilities, or review the configuration of facilities location problem.

The relationship with the walkers will continue analysis in the research. The spatial configuration is expected 
to be a simple, efficient application method which will be used by planner. Next, our survey will relate to pedestrian circulation, deep understanding of Space Syntax theory and the evaluation of the impact of spatial characteristics in the elements to discover the problems and propose solutions for improvement.

\section{References}

[1] Hillier, B. (2001) A Theory of the City as Object. Proceedings 3rd Space Syntax International Symposium, Atlanta, 02.

[2] Talav Era, R. (2012) Improving Pedestrian Accessibility to Public Space through Space Syntax Analysis. Proceedings: Eighth International Space Syntax Symposium, PUC, Santiago, Paper ref \# 8223.

[3] Jiang, B., Claramunt, C. and Klarqvist, B. (2000) Integration of Space Syntax into GIS for Modelling Urban Spaces. International Journal of Applied Earth Observation and Geoinformation, 2, 161-171.

[4] Kim, H.-K. and Sohn, D.W. (2002) An Analysis of the Relationship between Land Use Density of Office Buildings and Urban Street Configuration: Case Studies of Two Areas in Seoul by Space Syntax Analysis. Cities, 19, 409-418. http://dx.doi.org/10.1016/S0264-2751(02)00071-9

[5] Önder, D.E. and Gigi, Y. (2010) Reading Urban Spaces by the Space-Syntax Method: A Proposal for the South Haliç Region. Cities, 27, 260-227. http://dx.doi.org/10.1016/j.cities.2009.12.006

[6] van der Hoeven, F. and van Nes, A. (2014) Improving the Design of Urban Underground Space in Metro Stations Using the Space Syntax Methodology. Tunnelling and Underground Space Technology, 40, 64-74. http://dx.doi.org/10.1016/j.tust.2013.09.007

[7] Mahmoud, A.H. (2014) Planting Design for Urban Parks: Space Syntax as a Landscape Design Assessment Tool. http://www.sciencedirect.com/science/article/pii/S2095263514000594 